\title{
Clinical significance and efficacy analysis of atorvastatin in the treatment of patients with cerebral infarction and aspiration pneumonia
}

\author{
BING WEI and YUGENG LIU
}

\author{
Department of Emergency Medicine, Beijing Chaoyang Hospital Jingxi Branch, \\ Capital Medical University, Beijing 100043, P.R. China
}

Received March 19, 2018; Accepted September 6, 2018

DOI: $10.3892 / \mathrm{etm} .2018 .6829$

\begin{abstract}
Therapeutic efficacy of the use of oral atorvastatin in the treatment of patients with aspiration pneumonia complicated with cerebral infarction was investigated. Three hundred and fourteen cerebral infarction patients complicated with aspiration pneumonia who were admitted to the emergency department of Beijing Chaoyang Hospital Jingxi Branch from May 2015 to July 2017 were retrospectively analyzed. Among them, 160 patients who took atorvastatin were treated as observation group, and the remaining 154 patients were the control group. Patients were given basic treatment after diagnosis, and atorvastatin was also used for patients in the observation group. Venous blood was extracted to detect blood lipids and inflammatory cytokines. Patients were followed up for a period of six months, and the mortality was recorded. After treatment, blood lipid function and inflammatory factors in both groups were significantly improved $(\mathrm{P}<0.05)$. Hospital stay in the observation group $(86.88 \%)$ was significantly shorter than that in the control group $(76.33 \%)$ $(\mathrm{P}<0.01)$. After treatment, levels of TC, LDL, TG and CRP in the observation group $(86.25 \%)$ were significantly lower than those in the control group (76.32\%) $(\mathrm{P}=0.01)$. However, after treatment, level of HDL-C in the observation group $(11.88 \%)$ was significantly higher than that in the control group (23.38\%) $(\mathrm{P}=0.01)$. After treatment, levels of IL-6, IL-8 and TNF- $\alpha$ in the observation group were significantly lower than those in the control group $(\mathrm{P}<0.01)$. Total effective rate in the observation group was significantly higher than that of the control group $(\mathrm{P}=0.01)$. Total death rate in the observation group was significantly lower than that in the control
\end{abstract}

Correspondence to: Dr Yugeng Liu, Department of Emergency Medicine, Beijing Chaoyang Hospital Jingxi Branch, Capital Medical University, 5 Jingyuan Road, Shijingshan, Beijing 100043, P.R. China

E-mail: yugeng_liu@126.com

Key words: cerebral infarction, aspiration pneumonia, atorvastatin, efficacy analysis, lipid, inflammatory factor group ( $\mathrm{P}=0.02)$. In conclusion, atorvastatin is effective in the treatment of cerebral infarction patients complicated with aspiration pneumonia.

\section{Introduction}

Cerebral infarction is cerebral blood artery atherosclerosis or thrombosis caused by cerebral insufficiency (1). Another cause of cerebral infarction is abnormal blood flow (fluid, gas) into the cerebral artery caused by blood flow interruption or sudden loss of blood flow caused by tissue necrosis (2). Cerebral infarction occurs frequently in the middle-aged and elderly people. According to the report of Jabbarli et al (3), there are approximately 600,000 new cerebral infarction patients worldwide in 2015. With the growth of aging population, incidence of cerebral infarction shows an increasing trend (4). In addition, onset age of this disease is becoming increasingly younger (5). Cerebral infarction is currently the most common type of cerebrovascular disease with a high rate of disability and recurrence (6). Fu et al (7) reported that mortality rate of cerebral infarction patients has reached $28 \%$, and the recurrence rate was as high as $45 \%$. Due to the high incidence, mortality and recurrence of cerebral infarction, treatment of this disease is attracting increasing attention.

Due to insufficient blood circulation and supply, and reduced immune dysfunction, cerebral infarction patients are highly susceptible to concurrent disease (8), which in turn increases the difficulties in the treatment of this disease. Kalra et al (9) reported that approximatly $15 \%$ of patients with cerebral infarction were affected by aspiration pneumonia. Effective treatment of cerebral infarction complicated with aspiration pneumonia remains unsatisfactory. Atorvastatin is a selective and competitive inhibitor of $\mathrm{HMG}-\mathrm{CoA}$ reductase that can convert hydroxymethylglutaryl coenzyme A to mevalonate $(10)$. At present, studies $(11,12)$ have proved that atorvastatin has satisfactory clinical values in the treatment of patients with cerebral infarction, and no study has pointed out that atorvastatin can cause adverse reactions to lung. Therefore, we suppose that atorvastatin can also be used in the treatment of patients with cerebral infarction and aspiration pneumonia. Our study provided references for the treatment of cerebral infarction and aspiration pneumonia. 


\section{Materials and methods}

Patients. Clinical data of 314 patients with cerebral infarction complicated with aspiration pneumonia who were admitted to the emergency department of Beijing Chaoyang Hospital (Beijing, China) from May 2015 to July 2017 were retrospectively analyzed. There were 172 males and 142 females, and the age ranged from 45 to 65 years, with an average age of $52.35 \pm 9.72$ years. Among them, 160 patients who took atorvastatin were treated as the observation group, and the remaining 154 patients were the control group.

Inclusion and exclusion criteria. Inclusion criteria: Patients aged 45-65 years; diagnosed with cerebral infarction in Beijing Chaoyang Hospital; with aspiration pneumonia; received treatments in the hospital; willing to cooperate with researchers; and patients with complete clinical data. Exclusion criteria: Patients treated with statins during the past two months; with other cardiovascular and cerebrovascular diseases; with family disease history; with a history of cancer; with other respiratory diseases; drug-sensitive patients; pregnant patients; transferred to other hospitals during treatment; with physical disabilities; and patients that accepted non-hospital treatment. The study was approved by the Ethics Committee of Beijing Chaoyang Hospital, Capital Medical University (Beijing, China). Signed informed consents were obtained from the patients or the guardians.

Methods. Both groups of patients underwent basic treatment after diagnosis and treatments were conducted in strict accordance with the guidelines for treatment of cerebral infarction 2013 (13) (Table I). Besides basic treatment, patients in the observation group also received atorvastatin (oral medication, 20 mg/day, state approval no. H20120021; Guangdong Baihe Medical Technology Co., Ltd., Guandong, China). Two groups of patients were continuously treated for 2 months, and other types of lipid-lowering drugs and anti-bacterial drugs were not used during treatment. Venous blood (4 ml) was extracted from two groups of patients before and after treatment. Beckman Coulter AU5800 automatic biochemical analyzer (Beckman Coulter, Inc., Brea, CA, USA) was used to detect blood lipids and C-reactive protein (CRP). Serum levels of inflammatory cytokines were measured by ELISA. Neurological score of the patients was evaluated according to 2013 Neurological Function Scale (14). Length of hospital stay and the recovery of aspiration pneumonia in both groups were recorded. Patients were followed up for a period of six months and the mortality rate was recorded.

Observation indicators and evaluation criteria. Observations indicators: Clinical data of the two groups of patients; CRP; inflammatory factors: IL-6, IL- 8 and TNF- $\alpha$; hospitalization; prognosis survival rate.

Cerebral infarction rehabilitation evaluation criteria: Decline of neurological deficit score of $91-100 \%$ was excellent, decline of $46-90 \%$ was good, decline of $18-45 \%$ as fair, and decline $<17 \%$ was considered as poor. Total efficiency $=$ excellent rate + good rate. Evaluation of pneumonia rehabilitation was performed according to the guidelines for the treatment of inflammatory
Table I. Basic treatment.

\begin{tabular}{lcccc}
\hline $\begin{array}{l}\text { Treatment } \\
\text { content }\end{array}$ & Drug & $\begin{array}{c}\text { Way of } \\
\text { administration }\end{array}$ & $\begin{array}{c}\text { Dosage } \\
(\mathrm{mg})\end{array}$ & $\begin{array}{c}\text { Times } \\
\text { per day }\end{array}$ \\
\hline $\begin{array}{l}\text { Intracranial } \\
\text { pressure } \\
\text { dehydration }\end{array}$ & Mannitol & $\begin{array}{c}\text { Intravenous } \\
\text { injection }\end{array}$ & 125 & 3 \\
$\begin{array}{l}\text { Hypoglycemic } \\
\text { treatment }\end{array}$ & $\begin{array}{c}\text { Acarbose } \\
\text { tablets } \\
\text { Antihypertensive } \\
\text { Nifedipine } \\
\text { controlled }\end{array}$ & $\begin{array}{c}\text { Oral } \\
\text { treatment } \\
\text { treatment }\end{array}$ & 50 & 3 \\
$\begin{array}{l}\text { Anti-platelet } \\
\text { aggregation }\end{array}$ & $\begin{array}{c}\text { Aspirin } \\
\text { release tablets } \\
\text { teric-coated } \\
\text { tablets }\end{array}$ & Oral & 100 & 1 \\
& treatment & & 1 \\
\hline
\end{tabular}

Table II. Comparison of clinical data between two groups of patients $(\mathrm{n}, \%)$.

\begin{tabular}{lcccc}
\hline Variable & $\begin{array}{c}\text { Observation } \\
(\mathrm{n}=160)\end{array}$ & $\begin{array}{c}\text { Control } \\
(\mathrm{n}=154)\end{array}$ & $\mathrm{t} / \chi^{2}$ & P-value \\
\hline Age (years) & $54.83 \pm 8.69$ & $55.94 \pm 9.09$ & 1.11 & 0.27 \\
Weight (kg) & $82.35 \pm 7.42$ & $81.62 \pm 8.04$ & 0.84 & 0.40 \\
Onset time (h) & $16.24 \pm 2.54$ & $16.05 \pm 3.06$ & 0.60 & 0.55 \\
Sex & & & 0.09 & 0.76 \\
$\quad$ Male & $150(60.00)$ & $154(63.64)$ & & \\
Female & $100(40.00)$ & $88(36.36)$ & & \\
Smoking & & & 0.29 & 0.59 \\
$\quad$ Yes & $138(55.20)$ & $129(53.31)$ & & \\
No & $112(44.80)$ & $113(46.69)$ & & \\
\hline
\end{tabular}

Table III. Comparison of CRP before and after treatment $(\mathrm{mg} / \mathrm{ml})$.

\begin{tabular}{lcccc}
\hline Treatment & $\begin{array}{c}\text { Observation } \\
(\mathrm{n}=160)\end{array}$ & $\begin{array}{c}\text { Control } \\
(\mathrm{n}=154)\end{array}$ & $\mathrm{t}$ & P-value \\
\hline Before & $6.15 \pm 0.82$ & $6.19 \pm 0.90$ & 0.52 & 0.61 \\
After & $3.65 \pm 0.68^{\mathrm{a}}$ & $4.82 \pm 0.75^{\mathrm{a}}$ & 18.21 & $<0.01$ \\
\hline
\end{tabular}

${ }^{\mathrm{a}} \mathrm{P}<0.05$, compared with the pretreatment level within the same group. CRP, C-reactive protein.

diseases 2013 (15). Levels of inflammatory factors lower than normal were rehabilitated.

Statistical methods. Data were analyzed using SPSS 22.0 statistical software (IBM Corp., Armonk, NY, USA). Measurement data were expressed as mean \pm standard deviation (SD), and comparisons between two groups were performed by t-test. Intragroup comparisons were performed 
Table IV. Comparison of levels of inflammatory cytokines before and after treatment $(\mathrm{pg} / \mathrm{ml})$.

\begin{tabular}{lcccc}
\hline Variables & $\begin{array}{c}\text { Observation } \\
(\mathrm{n}=160)\end{array}$ & $\begin{array}{c}\text { Control } \\
(\mathrm{n}=154)\end{array}$ & $\mathrm{t}$ & P-value \\
\hline Before & & & & \\
IL-6 & $69.58 \pm 11.63$ & $71.34 \pm 12.88$ & 1.27 & 0.20 \\
IL-8 & $86.34 \pm 10.59$ & $85.92 \pm 11.31$ & 0.34 & 0.73 \\
TNF- $\alpha$ & $169.45 \pm 19.82$ & $172.62 \pm 22.13$ & 1.34 & 0.18 \\
After & & & & \\
IL-6 & $32.53 \pm 9.82^{\mathrm{a}}$ & $48.16 \pm 8.34^{\mathrm{a}}$ & 15.17 & $<0.01$ \\
IL-8 & $31.35 \pm 6.72^{\mathrm{a}}$ & $51.34 \pm 8.36^{\mathrm{a}}$ & 23.40 & $<0.01$ \\
TNF- $\alpha$ & $61.45 \pm 12.67^{\mathrm{a}}$ & $89.85 \pm 11.09^{\mathrm{a}}$ & 21.10 & $<0.01$ \\
\hline
\end{tabular}

${ }^{\mathrm{a}} \mathrm{P}<0.05$, compared with the pretreatment level within the same group.

Table V. Comparison of therapeutic efficacy between two groups $(\mathrm{n}, \%)$.

\begin{tabular}{lcccc}
\hline Variables & $\begin{array}{c}\text { Observation } \\
(\mathrm{n}=160)\end{array}$ & $\begin{array}{c}\text { Control } \\
(\mathrm{n}=154)\end{array}$ & $\mathrm{t} / \chi^{2}$ & P-value \\
\hline $\begin{array}{l}\text { Hospital stay } \\
\text { (days) }\end{array}$ & $21.85 \pm 8.62$ & $32.37 \pm 11.26$ & 9.32 & $<0.01$ \\
$\begin{array}{l}\text { Excellent } \\
\text { Good }\end{array}$ & $60(37.50)$ & $35(22.73)$ & & \\
$\begin{array}{l}\text { Fair } \\
\text { Poor }\end{array}$ & $20(49.38)$ & $81(52.60)$ & & \\
$\begin{array}{l}\text { Total efficacy } \\
\text { rate }(\%)\end{array}$ & $1(0.63)$ & $44(22.08)$ & & \\
Pneumonia & 86.88 & 75.33 & 6.86 & 0.01 \\
rehabilitation & $138(86.25)$ & $116(75.32)$ & 6.06 & 0.01 \\
& & & & \\
\end{tabular}

w paired t-test. Enumeration data are expressed as rates, and Chi-square tests were used for comparisons among groups. Kaplan-Meier was used for survival analysis, and log-rank test was used for testing. $\mathrm{P}<0.05$ was considered to indicate a statistically significant difference.

\section{Results}

Comparison clinical data. There was no significant difference in age, weight, onset time, sex composition and smoking habits between two groups of patients $(\mathrm{P}>0.05)$ (Table II).

Comparison of CRP before and after treatment. Before treatment, CRP were found between two groups of patients $(\mathrm{P}=092)$. After treatment, indicators of both groups were improved significantly $(\mathrm{P}<0.05)$. After treatment, levels of CRP in the observation group were significantly lower than those in the control group $(\mathrm{P}<0.01)$ (Table III).

Comparison of levels of inflammatory cytokines before and after treatment. Before treatment, no significant differences in levels of IL-6, IL- 8 and TNF- $\alpha$ were found between the two
Table VI. Prognosis survival rate $(\mathrm{n}, \%)$.

\begin{tabular}{lcccc}
\hline Variables & $\begin{array}{c}\text { Observation } \\
(\mathrm{n}=160)\end{array}$ & $\begin{array}{c}\text { Control } \\
(\mathrm{n}=154)\end{array}$ & $\chi^{2}$ & P-value \\
\hline $\begin{array}{l}\text { Survival rate in } \\
\text { the 1st month }\end{array}$ & $154(96.35)$ & $140(90.91)$ & 3.753 & 0.053 \\
$\begin{array}{l}\text { Survival rate in } \\
\text { the 3rd month }\end{array}$ & $149(93.13)$ & $129(83.77)$ & 6.771 & 0.009 \\
$\begin{array}{l}\text { Survival rate in } \\
\text { the 6th month }\end{array}$ & $141(88.13)$ & $118(76.62)$ & 7.185 & 0.007 \\
& & & &
\end{tabular}

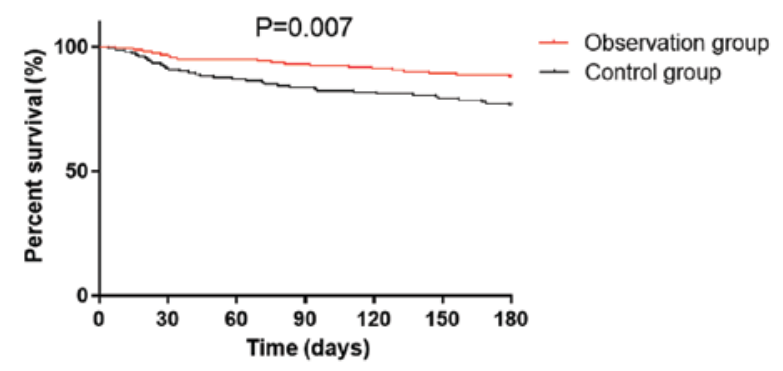

Figure 1. Survival of two groups. Survival curve analysis showed that the patients taking atorvastatin had a higher overall survival rate than those without atorvastatin for 6 months $(\mathrm{P}=0.007)$.

groups of patients $(\mathrm{P}>0.05)$. After treatment, levels of inflammatory cytokines were significantly improved in both groups $(\mathrm{P}<0.05)$. After treatment, levels of IL-6, IL-8 and TNF- $\alpha$ in the observation group were significantly lower than those in the control group $(\mathrm{P}<0.01)$ (Table IV).

Comparison of therapeutic efficacy between two groups. Hospital stay in the observation group was $21.85 \pm 8.62$ days, which was significantly shorter than that in the control group $32.37 \pm 11.26$ days $(\mathrm{P}<0.01)$. Excellent, good, fair and poor rate of the observation group were $37.50,49.38,12.50$ and $0.63 \%$, respectively, while in the control group were 22.73, 52.60, 22.08 and $2.60 \%$, respectively. Compared with the control group $(75.33 \%)$, total efficacy was significantly higher in the observation group $(86.88 \%)(\mathrm{P}=0.01)$. In the observation group $(86.25 \%, 138$ cases) of patients with pneumonia recovered significantly, which was significantly better than that of the control group (75.32\%, 116 cases) $(\mathrm{P}<0.05)$ (Table V).

Prognosis survival rate. The patients were followed up for a period of six months, and 312 patients completed the follow-up, and follow-up success rate was $99.36 \%$. Six patients were lost during follow-up, including 2 in the observation group and 4 in the control group. Survival rates in the observation group were $96.35,93.13$ and $88.13 \%$ in the first, third and sixth month, and $90.91,83.77$ and $76.62 \%$ in the control group, respectively (Table VI). The survival curve is shown is Fig. 1.

\section{Discussion}

Cerebral infarction is extremely harmful and has great negative impacts on health. In severe cases, cerebral infarction 
may lead to disability in self-care and even death (16). With the development and progress of medical technology, prognosis of patients with cerebral infarction has been improved. However, incidence and mortality of cerebral infarction are still on the rise due to accelerated population aging and differences in regional medical conditions (17). Patients with cerebral infarction complicated with aspiration pneumonia are more difficult to treat because of concurrent infection diseases, and their prognosis is even worse. Universal standard for the clinical treatment of those patients remains unknown, and cerebral infarction and aspiration pneumonia are usually separately treated. However, different drugs may cause different reactions, leading to poor treatment outcomes (18). In this study, we analyzed the efficacy of the use of atorvastatin alone in the treatment of patients with cerebral infarction complicated with aspiration pneumonia. The aim of this study is to provide references for the treatment of this disease.

Results of this study showed that the CRP levels in the observation group treated with atorvastatin combined with basic treatment were significantly lower than those in patients of the control group who were only treated with basic therapy $(\mathrm{P}<0.01)$. However, after treatment, HDL-C in the observation group was significantly higher than that in the control group $(\mathrm{P}<0.01)$. After treatment, levels of inflammatory cytokines IL-6, IL-8 and TNF- $\alpha$ in the observation group were significantly lower than those in the control group $(\mathrm{P}<0.01)$. Hospital stay and treatment efficiency of the observation group were also better than those of the control group $(\mathrm{P}<0.05)$. The sixmonth follow-up of all patients showed that the half-year total mortality (11.88\%) in the observation group was significantly lower than that in the control group $(23.38 \%, \mathrm{P}=0.01)$.

These data indicate that atorvastatin treatment can effectively reduce the levels of blood lipids and inflammatory factors in patients with cerebral infarction and aspiration pneumonia and can improve prognosis. Du et al (19) also showed that the application of atorvastatin in the treatment of cerebral infarction can reduce the levels of inflammatory cytokines. Elevated levels of TC and TG is the main cause of the formation of cerebrovascular endocardial atherosclerotic plaque in patients with cerebral infarction, and high TC and TG levels can also lead to increased plasma viscosity and abnormal platelet aggregation (20). Therefore, lipid-lowering is important for the treatment of patients with cerebral infarction. Atorvastatin has a strong regulatory effect on platelets (21), which can intervene abnormal blood flow and reduce levels of blood lipids and cholesterol in the body. Increased HDL-C level can protect patient's arterial wall to maintain smooth blood flow, which in turn avoid the formation of thrombosis on the blood vessel wall caused by the accumulation of LDL (22). In addition, atorvastatin can reduce the production of inflammatory cytokines in the blood by regulating blood lipids (23). In this study, levels of IL-6, IL-8, TNF- $\alpha$ were significantly reduced in the observation group patients compared with the control group, suggesting that atorvastatin not only can regulate the level of blood lipids, but also can inhibit inflammatory responses in those patients. Atorvastatin can inhibit the secretion of inflammatory cytokines in patients to inhibit the formation of macrophage tissue factor-induced plaque, so as to relieve carotid atherosclerosis and prevent the recurrence of cerebral infarction, thereby increasing the survival rate of patients (24).
This study is also limited by some shortcomings. Patients from different regions with different ethics backgrounds were not included and the follow-up is relatively short. We will solve these problems in our future studies.

In conclusion, atorvastatin is effective in the treatment of cerebral infarction patients complicated with aspiration pneumonia. Atorvastatin has satisfactory inhibitory effect on inflammation and can improve the prognosis of patients. So, it should be popularized in clinical practice.

\section{Acknowledgements}

Not applicable.

\section{Funding}

No funding was received.

\section{Availability of data and materials}

The datasets used and/or analyzed during the present study are available from the corresponding author on reasonable request.

\section{Authors' contributions}

BW was responsible for the conception and design of the study, and drafted the manuscript. BW and YL collected, analyzed and interpreted the patient data, and revised the manuscript for important intellectual content. Both authors read and approved the final manuscript.

\section{Ethics approval and consent to participate}

The study was approved by the Ethics Committee of Beijing Chaoyang Hospital, Capital Medical University (Beijing, China). Signed informed consents were obtained from the patients or the guardians.

\section{Patient consent for publication}

Not applicable.

\section{Competing interests}

The authors declare that they have no competing interests.

\section{References}

1. Tan XL, Xue YQ, Ma T, Wang X, Li JJ, Lan L, Malik KU, McDonald MP, Dopico AM and Liao FF: Partial eNOS deficiency causes spontaneous thrombotic cerebral infarction, amyloid angiopathy and cognitive impairment. Mol Neurodegener 10: 24, 2015.

2. Zeng Q, Lin K, Yao M and Wei L: Significant correlation between cystatin $\mathrm{C}$, cerebral infarction, and potential biomarker for increased risk of stroke. Curr Neurovasc Res 12: 40-46, 2015.

3. Jabbarli R, Reinhard M, Roelz R, Shah M, Niesen WD, Kaier K, Taschner C, Weyerbrock A and Van Velthoven V: Early identification of individuals at high risk for cerebral infarction after aneurysmal subarachnoid hemorrhage: The BEHAVIOR score. J Cereb Blood Flow Metab 35: 1587-1592, 2015.

4. Ye H, Wang L, Yang XK, Fan LP, Wang YG and Guo L: Serum S100B levels may be associated with cerebral infarction: A meta-analysis. J Neurol Sci 348: 81-88, 2015. 
5. Ye L, Cai R, Yang M, Qian J and Hong Z: Reduction of the systemic inflammatory induced by acute cerebral infarction through ultra-early thrombolytic therapy. Exp Ther Med 10: 1493-1498, 2015

6. Jabbarli R, Reinhard M, Niesen WD, Roelz R, Shah M, Kaier K, Hippchen B, Taschner C and Van Velthoven V: Predictors and impact of early cerebral infarction after aneurysmal subarachnoid hemorrhage. Eur J Neurol 22: 941-947, 2015.

7. Fu HJ, Zhao LB, Xue JJ, Wu ZX, Huang YP, Liu W and Gao Z: Elevated serum homocysteine (Hcy) levels may contribute to the pathogenesis of cerebral infarction. J Mol Neurosci 56: 553-561, 2015.

8. Wu W, Guan Y, Xu K, Fu XJ, Lei XF, Lei LJ, Zhang ZQ, Cheng Y and Li YQ: Plasma homocysteine levels predict the risk of acute cerebral infarction in patients with carotid artery lesions. Mol Neurobiol 53: 2510-2517, 2016.

9. Kalra L, Irshad S, Hodsoll J, Simpson M, Gulliford M, Smithard D, Patel A and Rebollo-Mesa I; STROKE-INF Investigators: Prophylactic antibiotics after acute stroke for reducing pneumonia in patients with dysphagia (STROKE-INF): A prospective, cluster-randomised, open-label, masked endpoint, controlled clinical trial. Lancet 386: 1835-1844, 2015.

10. Yang JW and Hu ZP: Neuroprotective effects of atorvastatin against cerebral ischemia/reperfusion injury through the inhibition of endoplasmic reticulum stress. Neural Regen Res 10: $1239-1244,2015$

11. Yang N, Lin M, Wang BG, Zeng WY, He YF, Peng HY, Zeng J, $\mathrm{Wu} \mathrm{ZY}$ and Zhong Y: Low level of low-density lipoprotein cholesterol is related with increased hemorrhagic transformation after acute ischemic cerebral infarction. Eur Rev Med Pharmacol Sci 20: 673-678, 2016.

12. Fang X, Tao D, Shen J, Wang Y, Dong X and Ji X: Neuroprotective effects and dynamic expressions of MMP9 and TIMP1 associated with atorvastatin pretreatment in ischemia-reperfusion rats. Neurosci Lett 603: 60-65, 2015.

13. Kumar A, Brown R, Dhar R, Sampson T, Derdeyn CP, Moran CJ and Diringer MN: Early vs. delayed cerebral infarction after aneurysm repair after subarachnoid hemorrhage. Neurosurgery 73: 617-623, 2013.

14. Chen B, Grothe $C$ and Schaller K: Validation of a new neurological score (FOUR Score) in the assessment of neurosurgical patients with severely impaired consciousness. Acta Neurochir (Wien) 155: 2133-2139, 2013

15. Whyte J, Nordenbo AM, Kalmar K, Merges B, Bagiella E, Chang H, Yablon S, Cho S, Hammond F, Khademi A, et al: Medical complications during inpatient rehabilitation among patients with traumatic disorders of consciousness. Arch Phys Med Rehabil 94: 1877-1883, 2013.
16. Li RY, Cao ZG, Li Y and Wang RT: Increased whole blood viscosity is associated with silent cerebral infarction. Clin Hemorheol Microcirc 59: 301-307, 2015.

17. Koh SH and Lo EH: The role of the PI3K pathway in the regeneration of the damaged brain by neural stem cells after cerebral infarction. J Clin Neurol 11: 297-304, 2015.

18. Honeybul S, Ho KM and Gillett G: Outcome following decompressive hemicraniectomy for malignant cerebral infarction: Ethical considerations. Stroke 46: 2695-2698, 2015.

19. Du R, Teng JF, Wang Y, Zhao XY and Shi ZB: Clinical study of Butylphthalide combined with Xue Shuan Tong on serum inflammatory factors and prognosis effect of patients with cerebral infarction. Pak J Pharm Sci 28 (Suppl): 1823-1827, 2015.

20. Yang N, Lin M, Wang BG, Zeng WY, He YF, Peng HY, Zeng J, Wu ZY and Zhong Y: Low level of low-density lipoprotein cholesterol is related with increased hemorrhagic transformation after acute ischemic cerebral infarction. Eur Rev Med Pharmacol Sci 20: 673-678, 2016

21. Kucera M, Balaz D, Kruzliak P, Ciccocioppo R, Oravec S, Rodrigo L, Zulli A, Hirnerova E, Sabaka P, Komornikova A, et al: The effects of atorvastatin treatment on the mean platelet volume and red cell distribution width in patients with dyslipoproteinemia and comparison with plasma atherogenicity indicators - A pilot study. Clin Biochem 48: 557-561, 2015.

22. Wu W, Guan Y, Xu K, Fu XJ, Lei XF, Lei LJ, Zhang ZQ, Cheng Y and Li YQ: Plasma homocysteine levels predict the risk of acute cerebral infarction in patients with carotid artery lesions. Mol Neurobiol 53: 2510-2517, 2016

23. Zhang J, Mu X, Breker DA, Li Y, Gao Z and Huang Y: Atorvastatin treatment is associated with increased BDNF level and improved functional recovery after atherothrombotic stroke. Int J Neurosci 127: 92-97, 2017.

24. Pantan R, Tocharus J, Suksamrarn A and Tocharus C: Synergistic effect of atorvastatin and Cyanidin-3-glucoside on angiotensin II-induced inflammation in vascular smooth muscle cells. Exp Cell Res 342: 104-112, 2016.

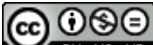

This work is licensed under a Creative Commons Attribution-NonCommercial-NoDerivatives 4.0 International (CC BY-NC-ND 4.0) License. 